\title{
Física e Poesia: diálogos e potencialidades no ensino de Física ${ }^{+*}$
}

\author{
Monikeli Wippel ${ }^{l}$ \\ Universidade Estadual de Campinas \\ Campinas - SP \\ Camila Silveira ${ }^{1}$ \\ Universidade Federal do Paraná \\ Curitiba - PR
}

\section{Resumo}

Versos de Mário de Sá-Carneiro, James Clerk Maxwell, Manuel Bandeira, Vinicius de Moraes, António Gedeão, Cecília Meireles, entre outros(as) podem carregar nas entrelinhas temas da Física e possibilidades para explorar conteúdos cientificos. Objetivamos, a partir de um diálogo sobre Física e Poesia, apresentar a análise de alguns poemas e as potencialidades didáticas e formativas que eles revelam para o ensino de Física. O diálogo com a Poesia permite que o ensino de Física considere os contextos histórico, cultural, social, científico e artístico, visando a uma compreensão mais ampla do conhecimento científico e da realidade.

Palavras-chave: Ciência e Arte; Ensino de Física; Física e Poesia; Poemas; Poesia.

\footnotetext{
Abstract

${ }^{+}$Physics and Poetry: dialogues and potentialities in Physics teaching

* Recebido: agosto de 2019. Aceito: março de 2020.

${ }^{1}$ E-mails: monikeliwippel@gmail.com,camila@quimica.ufpr.br
}

Between the lines of the Mario de Sá-Carneiro, James Clerk Maxwell, Manuel Bandeira, Vinicius de Moraes, Antonio Gedeão, Cecilia Meireles, among others, there can be themes of Physics and hence the possibilities to explore some of these scientific contents. From the dialogue on physics and poetry, we aim to present the analysis of some 
poems and the didactic and formative potential that they reveal for the teaching of physics. The dialogue with poetry allows the teaching of physics to take into account the historical, cultural, social, scientific, and artistic contexts, aiming at a broader understanding of scientific knowledge and reality.

Keywords: Science and Art; Physics Teaching; Physics and Poetry; Poems; Poetry.

\section{Introdução}

O presente artigo traz um recorte de uma pesquisa de Mestrado em Ensino de Ciências, concluída, e está centrado na confluência entre Poesia e o Ensino de Física. O tema está inserido em um contexto mais amplo que contempla relações entre Ciência e Arte no Ensino de Física/Ciências e na formação docente.

Ciência e Arte são campos de criação humana, amplos e particulares, são "centros gêmeos de geratividade cultural” (WILSON, 2009, p. 489). Contudo, surgiram discussões quanto a considerar Ciência como cultura. Charles Percy Snow, romancista e físico britânico, autor do livro "As Duas Culturas", chamou atenção para esse fato e apontou que o abismo existente entre "cultura científica" e "cultura tradicional", onde uma é ignorante à outra, gera perdas para a sociedade, de ordem prática, intelectual ou criativa e que "quando esses dois sentidos se desenvolvem separados, nenhuma sociedade é capaz de pensar com sabedoria" (SNOW, 2015, p. 72).

A divisão do conhecimento humano e a aparente falta de comunicação entre as áreas provêm de outras épocas. A instrução humana, que anteriormente era baseada no domínio de áreas distintas, desde o Renascimento se tornou cada vez mais seccionada em áreas específicas (WILSON, 2009). Por conseguinte, "ciência e arte apertaram o passo na busca de suas próprias agendas esotéricas, enquanto a alfabetização geral em ambas as áreas está em declínio" (WILSON, 2009, p. 489).

Diferentes autores (ZANETIC, 2005, 2006; REIS, GUERRA, BRAGA, 2006, ARAUJO-JORGE et al., 2007; RANGEL; ROJAS, 2014) chamam atenção para a visão mais interessante que a Ciência e as diferentes formas de expressões artísticas e literárias proporcionam do mundo, e destacam o papel da criatividade e da imaginação como elementos importantes no desenvolvimento de atividades de cientistas e artistas.

Cientistas e artistas são sensiveis a novas ideias, a novos conceitos e imagens, à formação de hipóteses e projeções de fatos; ambos registram suas observações, suas descobertas, assim como suas preocupações e estranhamentos que mobilizam e justificam as motivações de suas pesquisas, inspirando seus sentimentos, seu modo próprio de "perceber" a vida e compartilhar suas percepções. Dessa forma, a obra de arte e a obra cientifica se entrelaçam nas manifestações do ato criativo, que é 
pessoal e único, ao mesmo tempo em que contém a universalidade da condição de ser humano, herdeiro e construtor da memória histórica e cultural da humanidade (RANGEL; ROJAS, 2014, p. 75).

Wilson (2009, p. 496) aponta que "as culturas prosperaram quando atividades que agora chamamos de ciência ou arte eram realizadas de forma unificada". Assim, seja no Cinema, na Dança, na Música, na Pintura, no Teatro ou na Poesia, é possível estabelecer relações com a Ciência, e isso também se revela algo promissor para uma aprendizagem mais profunda e conexa com o mundo. Nessa mesma linha, Nepote $(2012$, p. 20) relata que "o poeta Samuel Taylor Coleridge dizia que assistia às aulas de química 'para enriquecer minhas provisões de metáforas" da mesma forma que "o matemático Karl Weierstrass estava convencido de que 'um matemático que não tenha ao mesmo tempo algo de poeta não será nunca um matemático completo"”.

Desta forma, a partir de um diálogo entre Física e Poesia, o objetivo central deste artigo é apresentar a análise de alguns poemas bem como potencialidades didáticas e formativas para o ensino de Física.

\section{Física e Poesia}

Embora a compreensão do que seja Poesia possa suscitar amplas discussões, traçamos uma perspectiva apoiada em argumentos de autores como Moisés (1968, 1977), Paixão (1982), Lyra (1986), Moriconi (2002), Goldstein (2006), Perissé (2006) e Paz (2012).

Cabe frisar que, ao longo do tempo, poetas, leitores e estudiosos têm se referido à Poesia e ao poema como coisas diferentes e "são inúmeras as tentativas de definição, mas nenhuma se apresentou com a universalidade e o rigor necessários à sua afirmação estética, filosófica ou científica" (LYRA, 1986, p. 5). De acordo com Moisés (1977, p. 70), o vocábulo "poema" é "originário da mesma raiz de 'poesia' - poieîn (fazer)" e "tem sido empregado histórica e universalmente para designar o texto em que o fenômeno poético se realiza". Dessa forma, "nem todo poema - ou, para ser mais exato, nem toda obra construída de acordo com as leis do metro - contém poesia" (PAZ, 2012, p. 22). Nessa perspectiva:

Um soneto não é um poema, e sim uma forma literária, exceto quando esse mecanismo retórico - estrofes, metros e rimas - foi tocado pela poesia. Há máquinas de rimar, mas não de poetizar. Por outro lado, há poesia sem ser poemas. Pois bem, quando a poesia se dá como condensação do acaso ou é uma cristalização de poderes e circunstâncias alheios à vontade criadora do poema, deparamos com o poético. Quando - passivo ou ativo, acordado ou sonâmbulo - o poeta é o fio condutor e transformador da corrente poética, estamos na presença de uma coisa radicalmente diferente: uma obra. Um poema é uma obra. A poesia se polariza, congrega e isola em um produto humano: quadro, canção, tragédia. $O$ poético é poesia em estado amorfo; o poema é criação, poesia erguida (PAZ, 2012, p. 22). 
O diálogo entre Ciência e Poesia nasce na medida que percebemos que tanto uma como a outra são ricas e "alargam nossa imaginação, pois, em vez de confortar-nos com respostas, confrontam-nos com perguntas. Aguçam nosso olhar para explorar a surpresa e o mistério das coisas aparentemente mais ordinárias" (NEPOTE, 2012, p. 21).

Mesmo com características e linguagem específica, a Ciência pode ter uma dimensão poética, e "se o poema é uma tentativa expressiva, deduz-se que nem todo poema carrega poesia, e que nem toda poesia aparece como poema" (MOISÉS, 1968, p. 36). Para Moriconi (2002, p. 8), “toda linguagem tem seu quê de poesia. Mas Poesia é onde o 'quê' da linguagem está mais em pauta. A Poesia brinca com a linguagem. Chama atenção para as possibilidades de sentido". O mesmo autor aponta que "a palavra poesia abrange sentidos que vão além da linguagem verbal, oral ou escrita. Ela também se refere a um universo muito mais amplo e menos exclusivo ou especializado que o do livro e da leitura" (MORICONI, 2002, p. 8-9).

\begin{abstract}
É o lado além-livro da poesia. Que tem a ver com o universo todo da cultura, tem a ver com o ar que nos envolve. Um filme pode ter poesia. Um gesto, comum ou excepcional, pode ter poesia. A poesia está no ar. A poesia é popular, se mulher é flor, a poesia está na boca do povo, vem da boca do povo. Espera-se que a poesia enquanto arte especifica das palavras de algum modo revele ou esteja articulada com essa poesia além-livro, essa poesia da vida (MORICONI, 2002, p. 9).
\end{abstract}

Paz (2012, p. 22) indica que "o poema não é uma forma literária, mas o ponto de encontro entre a poesia e o homem. Poema é um organismo verbal que contém, suscita ou emite poesia". Nas palavras de Lyra "o poema é, de modo mais ou menos consensual, caracterizado como um texto escrito (primordialmente, mas não exclusivamente) em verso" (LYRA, 1986). Já a poesia é interpretada como sendo "complexa substância pura e imaterial, anterior ao poeta e independente do poema e da linguagem, e que apenas se concretiza em palavras como conteúdo do poema, mediante a atividade humana". Sobre esse ponto de vista, destacamos que os poemas são obras humanas - assim como a Ciência. No entanto, não há "entre um poema e outro a relação de filiação [...] cada poema é um objeto único, criado por uma 'técnica' que morre no momento exato da criação" (PAZ, 2012, p. 25). É claro que um poeta pode "compartilhar" procedimentos e características comuns na criação - o estilo - mas cada obra continua sendo única, evidenciando a subjetividade na criação do poema.

Há aqueles que parecem não seguir um estilo, o comum da sua época, é então que temos que considerar outros aspectos para a compreensão, pois se "estilos nascem, crescem e morrem" (PAZ, 2012, p. 2), devem haver motivos ou objetivos com essa transcendência.

Seguindo, Paz revela também que o poema não precisa ser exclusivo:

O poema é uma possibilidade aberta a todos [...] qualquer que seja seu temperamento, seu ânimo ou sua disposição. Pois bem, o poema é apenas isto: possibilidade, algo que só se anima em contato com um leitor ou um ouvinte. Há um traço comum a todos os poemas, sem o qual eles nunca seriam poesia: a participação. Toda vez que um leitor revive de verdade o poema, atinge um estado 
que podemos chamar poético. Tal experiência pode adquirir esta ou aquela forma, mas é sempre um ir além de si, um romper os muros temporais para ser outro. Tal como a criação poética, a experiência do poema se dá na história, é história e, ao mesmo tempo, nega a história (PAZ, 2012, p. 33).

E se o poema é uma possibilidade aberta a todos, é uma possibilidade também para aqueles que são de áreas afastadas - num primeiro olhar - da cultura literária. Não só no sentido de participar como leitor, mas buscando relações nessa "participação" que lhe façam algum sentido com sua própria realidade.

E será que pode a Poesia apresentar alguma relação com a realidade? No que tange essa relação, há mistérios, pois,

\begin{abstract}
A realidade, concebida como "dado da consciência", "atualidade" é mistério: "a presença é um mistério - não um enigma que excita a nossa curiosidade, mas mistério que reclama respeito. Toda presença tem um irredutivel núcleo de mistério, na medida em que retém seu caráter presencial. Explicações, teorias e problemas especificos são dirigidos para um objeto na sua coisidade, não na sua

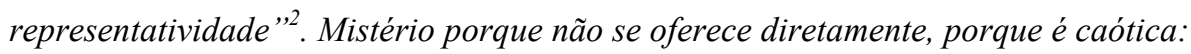
as coisas do mundo fisico se agrupam desordenadamente, sem unidade visivel e nexo de ligação ou causalidade. Como se ocultassem uma identidade, um liame secreto, impermeável às teorias, explicações e conceitos (MOISÉS, 1977, p. 139140).
\end{abstract}

Nesse contexto, a Filosofia, a Ciência e a Religião seriam entendidas como tentativas de ordenar o real, enquanto às Artes estaria reservada a função de buscar reproduzir o real, ou seja, seu mistério e seu caos (MOISÉS, 1977). Portanto, a Poesia, ao se espelhar em uma realidade misteriosa e ao ser criada como outra realidade, acaba configurando um mistério duplo.

Presença dúplice, uma refletida ou refratada, e a outra que é conferida pelo objeto no qual o mistério poético se inscreve. De onde o poema ser a ponte entre duas esferas misteriosas, ao mesmo tempo que a mediação entre o leitor e a realidade: procurando no poema a realidade que nela se hipnotiza, o leitor contempla outra realidade, a da poesia, coagulada em palavras (MOISÉS, 1977, p. 140).

Com a Física se caracterizando como uma forma de explicar o real em todo o seu mistério e caos, e a Poesia se caracterizando por esse mistério duplo, pensar em aproximações acaba se tornando um exercício a princípio complexo dado a quantidade de mistério e caos nessas realidades.

As aproximações entre Ciência e poesia revelam-se, no entanto, muito ricas, se olhadas dentro de um mesmo sentimento do mundo. A criatividade e a imaginação

\footnotetext{
${ }^{2}$ WHEELRIGHT, P. Metaphor and Reality. Bloomington: Indiana University Press, 1968.
} 
são o húmus comum de que se nutrem. Na origem desses dois movimentos, as incertezas de uma realidade complexa que demanda várias faces que podem transformar-se em versos, em gedankens ou ser representados por formas matemáticas. (MOREIRA, 2002, p. 17).

Nepote (2012) se utiliza das palavras do escritor Miguel García-Posada para enfatizar que as relações entre o saber científico e a arte poética são de ida e volta: "ao longo da história a poesia baseou-se em conceitos científicos para articular suas metáforas" e que "poesia e ciência têm em comum o traço preeminente que a intuição desempenha nelas... A poesia transcende o horizonte habitual, alcança um novo horizonte de sentido, a ciência inventa novas imagens para reescrever o mundo" (GARCIA-POSADA, 2012, apud NEPOTE, 2006).

Mecke (2004) aponta cinco peculiaridades de relações entre Física e Literatura, as quais servem também para relacionar especificamente com a Poesia. São elas: metáforas físicas, os físicos como personagens literárias, Física e sociedade - a responsabilidade do cientista, a literatura na mudança da Física e todas as ciências têm de ser poetizadas. Ao longo do texto, essas peculiaridades serão detalhadas nos comentários de poemas.

Reunimos aqui poemas que, ao nosso ver, possibilitam estabelecer relações com temas científicos e que também exemplificam os aspectos discutidos por Mecke. São alguns exemplos entre os diversos outros que poderiam ter sido escolhidos e, claro, "um professor, com imaginação, dedicação e tempo, poderá com certeza construir seu próprio conjunto de belos e instigantes poemas, todos eles associados a temas científicos" (MOREIRA, 2002, p. 17). Não é uma análise profunda, cabe destacar, mas uma tentativa de contextualizá-los e de ressaltar possíveis aproximações com a Física. Assim, “contextualizar o poema não é simplesmente datá-lo; é inserir as suas imagens e pensamentos em uma trama já em si mesma multidimensional" (BOSI, 2000, p. 13). Nesse momento, lembramos que "cada leitor procura alguma coisa no poema. E não é nada estranho que a encontre: já a tinha dentro de si” (PAZ, 2012, p. 32).

Os poemas escolhidos são de autoria de Mário de Sá-Carneiro, James Clerk Maxwell, Manuel Bandeira, Vinicius de Moraes, António Gedeão e Cecília Meireles.

O primeiro é A minha Alma Fugiu Pela Torre Eiffel Acima do poeta português Mário de Sá-Carneiro, datado de 1915 (SÁ-CARNEIRO, 1995):

A minha Alma, fugiu pela Torre Eiffel acima,/- A verdade é estar, não nos criemos mais ilusões/Fugiu, mas foi apanhada pela antena da TSF/Que a transmitiu pelo infinito em ondas hertzianas.../(Em todo o caso que belo fim para a minha Alma)!...(SÁ-CARNEIRO).

Sá-Carneiro explora o imaginário do sistema de telegrafia sem fio T.S.F. associado à Torre Eiffel, através do qual sinais e mensagens - e também sua própria alma - eram disseminados naquele período (VASCONCELOS, 2013). O poema esteve presente em uma carta escrita por Mário de Sá-Carneiro para o também poeta Fernando Pessoa. Os versos 
destacam a fragmentação do sujeito associado à modernidade. A alma foge pela torre acima, ninguém a detém e ela não cai, se dissemina universalmente, progredindo no infinito pelas ondas hertzianas. A disseminação pode ser a da identidade do sujeito moderno a partir da Torre Eiffel (símbolo da modernidade de Paris naquela época).

Ao utilizar conhecimentos da telegrafia sem fio o poeta valeu-se de conhecimentos científicos para extrair uma consequência literária, algo já assinalado por Mecke (2004) em a "literatura na mudança da Física": "há muito que os escritores se servem de conhecimentos físicos e extraem consequências literárias das novas maneiras de ver o mundo" (MECKE, 2004, p. 9).

A telegrafia sem fio já era usada no mundo no final do século XIX e desenvolvida por diferentes cientistas, mas a paternidade - por ter patenteado a "T.S.F" - é dada a Guglielmo Marconi ${ }^{3}$.

O modernismo parisiense, em seus aspectos históricos, sociais e artísticos é uma das possibilidades de diálogos nesse momento. O poema não é detalhista quanto a conteúdos científicos, mas, por exemplo, pensando no ensino, permite propor uma reflexão sobre sistemas de comunicação do período modernista e sistemas contemporâneos, a Física presente em tais processos, assuntos relacionados à ondulatória, etc. É importante considerar diferentes aspectos no momento da interpretação de um poema, pois "a poesia pertence à História Geral, mas é preciso conhecer qual é a história peculiar imanente e operante em cada poema" (BOSI, 2000, p. 13).

Sobre isso, Goldstein (GOLDSTEIN, 2006, p. 11) salienta que os poemas têm uma unidade, mas que ao analisá-lo "é possível isolar alguns de seus aspectos, em um procedimento didático, artificial e provisório". Logo, em um processo análogo, procuramos evidenciar possíveis diálogos com a Física/Ciência, apontando possibilidades didáticas, sem, no entanto, "perder de vista a unidade do texto a ser recuperada no momento da interpretação, quando o poema terá sua unidade orgânica restabelecida" (GOLDSTEIN 2006, p. 11).

O segundo poema escolhido foi Valentine by a telegraph Clerk, de autoria de James Clerk Maxwell (COLLINS, 2011):

The tendrils of my soul are tined/With thine, though many a mile apart./And thine in close coiled circuits wind/Around the needle of my heart.//Constant as Daniel, strong as Grove./Ebullient throughout its depths lie Smee,/My heart puts forth its tide of love,/And all its circuits close in thee.//O tell me, when along the line/From my full heart the message flows,/Whats currents are induced in thine?/One click from thee will end my woes.//Through many a volt the weber flew,/And clicked this answer back to me;/I am thy farad staunch and true,/Charged to a volt hit love for thee (COLLINS, 2011).

Em uma tradução livre para o português:

\footnotetext{
${ }^{3}$ Engenheiro e inventor italiano (1874-1937) que ganhou, em 1909, o Prêmio Nobel de Física (juntamente com Karl Ferdinand Braun) por suas contribuições para o desenvolvimento do telégrafo sem fio.
} 
Os tendões da minha alma são torcidos/como os seus, embora muitas milhas de distância./E o seu, em circuitos fechados, serpenteiam/ao redor da agulha do meu coração.//Constante como Daniel, forte como Grove./Exuberante em todas as suas profundezas, como Smee,/meu coração expõe sua maré de amor,le todos os seus circuitos se aproximam de ti.//Ou me dizer, quando ao longo da linha/A partir do meu coração cheio a mensagem flui,/que as correntes são induzidas no teu?/Um clique de você vai acabar com minhas aflições.//Através de vários volts weber voaram,/e clicaram nesta resposta de volta para mim;/Eu sou o seu farad firme e verdadeiro,/Carregado para um volt com amor por você.

Aqui resgatamos um dos aspectos abordados por Mecke (2004) sobre a História da Física e da Literatura caminharem juntas. Nesse contexto, é interessante pensar que personagens importantes na História - nesse caso, Maxwell - foram, ao mesmo tempo, cientistas e escritores.

[...] a história da fisica e a história da literatura andaram sempre de mãos dadas.

[...] O que não é de admirar uma vez que muitas pessoas que levaram "vidas duplas", como experimentadores e como escritores. James Clerk Maxwell não só desenvolveu a teoria do eletromagnetismo como escreveu poemas [...] (MECKE, 2004, p. 9).

Quem já ouviu falar de James Clerk Maxwell muito provavelmente foi em aulas de Física, já que ele é amplamente conhecido devido aos estudos sobre a Teoria Moderna do Eletromagnetismo. Quem imaginaria que o mesmo foi também um poeta? No poema exposto anteriormente Maxwell fala do seu amor comparando o sentimento que percorre o seu coração com a corrente em um circuito. No decorrer dos versos faz referência a um aparelho elétrico; a pilha de Daniell fornecia uma corrente mais constante, a de Grove uma maior força eletromotriz e na de Smee parecia que o ácido sulfúrico borbulhava intensamente (COLLINS, 2011). No âmbito do ensino, além de abordar simplesmente conteúdos de Eletromagnetismo é interessante contextualizar quem foi Maxwell, suas principais contribuições na Ciência, as possibilidades criativas e diversas de comunicar aspectos científicos, desmistificando, inclusive, a figura do cientista como alguém apenas trancado em um laboratório e muitas vezes desconexo de sentimentos como o amor, etc.

O terceiro poema é Satélite de Manuel Bandeira, originalmente publicado no livro Estrela da Tarde, em 1960 (BANDEIRA, 2005):

\footnotetext{
Fim de tarde./No céu plúmbeo/A lua baça/Paira/Muito cosmograficamente/Satélite.//Desmetaforizada,/Desmitificada,/Despojada do velho segredo de melancolia,/Não é agora o golfão de cismas,/O astro dos loucos e dos enamorados,/Mas tão somente/Satélite.//Ah Lua deste fim de tarde,/Demissionária de atribuições românticas,/Sem show para as disponibilidades sentimentais!/Fatigado de mais valia,/Gosto de ti assim:/Coisa em si,/- Satélite (BANDEIRA, 2005).
} 
Manuel Bandeira (1886-1968) foi um poeta brasileiro, professor de Literatura e também crítico de Arte.

Em Satélite, na primeira estrofe Bandeira descreve uma situação na qual o satélite natural da Terra é sem brilho, opaco no céu, o que poderia ser interpretado como um afastamento de ideias românticas ligadas à Lua. Nota-se, ainda, que utiliza um advérbio que não existe na língua portuguesa: cosmograficamente, e "como cosmografia é a astronomia descritiva, principalmente referente ao sistema solar, o que o poeta quer dizer como paira muito cosmograficamente é que a lua está no alto pura e simplesmente como um astro" (FIORIN, 2015, p. 105). Posteriormente, o poeta volta a afastar a ideia romântica sobre a Lua, colocando-a unicamente como o satélite natural da Terra ao fazer uso do advérbio de intensidade "tão" e "somente satélite", na segunda estrofe: "Mas tão somente/Satélite".

Um pensamento análogo surge quanto aos versos: "Ah Lua deste fim de tarde/Demissionária de atribuições românticas".

E novamente, no início da terceira estrofe, sendo explícito ao colocar "Lua" com letra maiúscula, referindo-se cientificamente ao satélite natural da Terra.

Ao fazer tais considerações parece que estamos mais perto do poeta. Claro que não podemos afirmar com toda certeza o que ele queria ao escrever o poema, muito menos que nossas interpretações são as únicas, entretanto parece que "a leitura do poema ativa o poeta que somos, o criador ou a criadora que somos, nesse sentido amplo da palavra" (MORICONI, 2002, p. 9-10). Ao fazer um paralelo com os aspectos apontados por Mecke (2004) é interessante refletir quando ele diz que "na rotina do nosso quotidiano de físicos esquecemonos frequentemente de que são as metáforas, e não as fórmulas, que constituem a espinha dorsal do pensamento" (MECKE, 2004, p. 11). Além disso:

Os conceitos e metáforas físicos encontram-se por quase toda a parte, em discursos e textos [...] Entre as mais populares encontram-se: magnético - no sentido de uma atracção sinistra e animal, frequentemente significando amor; salto quântico - no sentido de uma mudança superlativa; sinergia - no sentido de um misterioso fenómeno cooperativo [...] (MECKE, 2004, p. 6).

O mesmo autor argumenta também que, por ultrapassar conceitualmente as fórmulas abstratas as quais a ciência se detém, a literatura parece ser melhor do que as Ciências da Natureza. Completa o pensamento com os argumentos de Aristóteles e Novalis: Aristóteles argumentara que a literatura era a melhor historiografia, porque dá atenção à generalidade e não ao pormenor. E Novalis exigiu que todas as ciências fossem poetizadas como a única maneira de a humanidade alcançar a verdade (MECKE, 2004, p. 11).

Observa-se no poema a utilização do termo famosamente empregado por Karl Marx ${ }^{4}$ no $17^{\circ}$ verso: "Fatigado de mais valia"

\footnotetext{
${ }^{4}$ Economista, Filósofo e Socialista alemão (1818-1883).
} 
Nesse ponto há uma abertura para discussão interdisciplinar sobre o termo, que se refere ao valor excedente entre o valor final de uma mercadoria produzida e o valor necessário para essa produção (os meios de produção e a força de trabalho) (MARX, 2014, p. 220).

Cabe lembrar que essas são interpretações de aspectos que nos saltam aos olhos e que tais reflexões não devem ser levadas como únicas, pois:

\begin{abstract}
A interpretação dificilmente será a palavra final, se for feita por uma só pessoa. $O$ texto literário talvez seja aquele que mais se aproxima do sentido etimológico da palavra "texto": entrelaçamento, tecido. Como "tecido de palavras", o poema pode sugerir múltiplos sentidos, dependendo de como se perceba o entrelaçamento dos fios que o organizam. Ou seja: geralmente, ele permite mais de uma interpretação. Dada a plurissignificação inerente ao poema, a soma das várias interpretações seria o ideal (GOLDSTEIN, 2006, p. 12).
\end{abstract}

À vista disso, o poema possibilita pensar e discutir sobre aspectos científicos, sobre a Lua e sobre satélites (naturais ou artificiais) de forma geral. Abre oportunidade para debater sobre as funções dos satélites artificiais na sociedade, comunicação dos mesmos com a Terra, como são suas órbitas e como são levados a elas. Além disso, temas decorrentes como as influências da Lua no planeta Terra, sua estrutura e formação, também são provocados pelos versos de Bandeira.

Na sequência, temos o poema A Bomba Atômica, de Vinicius de Moraes (MORAES, 1992):

I/e $=$ mc2/EINSTEIN/Deusa, visão dos céus que me domina/...tu que és mulher $e$ nada mais!/("Deusa”, valsa carioca.)/Dos céus descendo/Meu Deus eu vejo/De pára-quedas?/Uma coisa branca/Como uma forma/De estatuária/talvez um seio/Despregando à lua/Talvez o anjo/Tutelar cadente/Talvez a Vênus/Nua de clâmide/Talvez a inversa/Branca pirâmide/Do pensamento/Talvez o troço/De uma coluna/Da eternidade/Apaixonado/Não sei indago/Dizem-me todos/É A BOMBA ATÔMICA/Vem-me uma angústia.//Quisera tanto/Por um momento/Tê-la em meus braços/E como ao vento/Descendo nua/Pelos espaços./Descendo brana/Branca e serena/Como um espasmo/Fria e corrupta/De longo sêmen/Da Via-Láctea/Deusa impoluta/O sexo abrupto/Cubo de prata/Mulher ao cubo/Caindo aos súcubos/Intemerata/Carne tão rija/De hormônios vivos/Exacerbada/Que o simples toque/Pode rompê-la/Em cada átomo/Numa explosão/Milhões de vezes/Maior que a força/Contida no ato/Ou que a energia $v$ Que expulsa o feto/Na hora do parto.//II/A bomba atômica é triste/Coisa mais triste não há/Quando cai, cai sem vontade/Vem caindo devagar/Tão devagar vem caindo/Que dá tempo a um passarinho/De pousar nela e voar.../Coitada da bomba atômica/Que não gosta de matar!/Coitada da bomba atômica/Que não gosta de matar/Mas que ao matar mata tudo/Animal e vegetal/Que mata a vida da terra/E mata a vida do ar/Mas que também mata a guerra.../Bomba atômica que aterra!/Bomba atônita da paz!/Pomba tonta, bomba atômica/Tristeza, consolação/Flor puríssima do urânio/Desabrochada no chão/Da cor pálida do hélium/E odor de rádium fatal/Lolia mineral carnívora/Radiosa rosa 
radical./Nunca mais oh bomba atômica/Nunca em tempo algum, jamais/Seja preciso que mates/Onde houve morte demais:/Fique apenas tua imagem/Aterradora miragem/Sobre as grandes catedrais:/Guarda de uma nova era/Arcanjo insigne da paz!//III/Bomba atômica, eu te amo! és pequenina/branca como a estrela vespertina/E por branca eu te amo, e por donzela/De dois milhões mais bélica e mais bela/Que a donzela de Orleães; eu te amo, deusa/Atroz, visão dos céus que me domina/Da cabeleira loura de platina/E das formas aerodivinais/- Que és mulher, que és mulher e nada mais!/Eu te amo, bomba atômica, que trazes/Numa dança de fogo, envolta em gazes/A desagregação tremenda que espedaça/A matéria em energias materiais!/Oh energia, eu te amo, igual à massa/Pelo quadrado da velocidade/Da luz! alta e violenta potestade/Serena! Meu amor... desce do espaço Vem dormir, vem dormir, no meu regaço/Para te proteger eu me encouraço/De canções e de estrofes magistrais!/Para te defender, levanto o braço/Paro as radiações espaciais/Uno-me aos líderes e aos bardos, uno-me/Ao povo ao mar e ao céu brado o teu nome/Para te defender, matéria dura/Que és mais linda, mais límpida e mais pura/Que a estrela matutina! Oh bomba atômica/Que emoção não me dá ver-te suspensa/Sobre a massa que vive e se condensa/Sob a luz! Anjo meu, fora preciso/Matar, com tua graça e teu sorriso/Para vencer? Tua enégica poesia/Fora preciso, oh deslembrada e fria/Para a paz? Tua fragílima epiderme/Em cromáticas brancas de cristais/Rompendo? Oh átomo, oh neurônio, oh germe/Da união que liberta da miséria!/Oh vida palpitando na matéria/Oh energia que és o que não eras/Quando o primeiro átomo incriado/Fecundou o silêncio das Esferas:/Um olhar de perdão para o passado/Uma anunciação de primaveras! (MORAES, 1992).

Nas relações entre Física e Literatura pode-se observar a presença de cientistas como personagens. Segundo Mecke (2004, p. 7) "a literatura reflete não só o saber da física como os próprios físicos e até a totalidade do empreendimento científico". Há poemas que trazem físicos e cientistas - ou resultados, ou consequências de seus trabalhos - como personagens, implícita ou explicitamente.

Vinicius de Moraes (1913-1980), poeta e compositor brasileiro, inicia o poema com a equação de equivalência massa-energia usada no desenvolvimento da Bomba Atômica. A energia liberada pela explosão do artefato também é destacada nos versos: "Oh energia, eu te amo, igual/à massa/Pelo quadrado da/velocidade".

O poeta compara essa energia com a energia com a qual um bebê é "expulso" da mãe no nascimento: "Que o simples toque/Pode rompê-la/Em cada átomo/Numa explosão/Milhões de vezes/maior que a força/Contida no ato/Ou que a energia /Que expulsa o feto/na hora do parto".

Ao trazer essa reflexão sobre a bomba atômica interpretamos que o trabalho do cientista está diretamente ligado à crueldade que aconteceu. No trecho "Coitada da bomba atômica", o poeta parece colocar a bomba na posição de vítima, digna de pena, uma vez que provoca destruição e está diretamente ligada a guerra. A criação/explosão da bomba poderia ser interpretada ainda como uma consequência das decisões de determinadas pessoas. Não é a 
bomba que quer matar, no fundo, isso só acontece porque tomaram a decisão de lançá-la: "Coitada da bomba atômica/Que não gosta de matar!/Coitada da bomba atômica/Que não gosta de matar/mas que ao matar mata tudo/Animal e vegetal/Que mata a vida da terra/E mata a vida do ar."

Uma observação de Mecke cabe na análise desse poema: "antes da Segunda Guerra Mundial o cientista era frequentemente visto como herói, mas a bomba atômica trouxe para lugar de destaque a ambivalência do processo científico" (MECKE, 2004, p. 4).

Vinicius, contemporâneo da Segunda Guerra Mundial, escreveu ainda A Rosa de Hiroxima (MORAES, 2006) retratando as consequências da crueldade resultante do lançamento das bombas atômicas nas cidades de Hiroshima e Nagazaki pelos Estados Unidos da América, em 1945:

$$
\begin{aligned}
& \text { Pensem nas crianças/Mudas e telepáticas/pensem nas meninas/Cegas } \\
& \text { inexatas/Pensem nas mulheres/Rotas alteradas/Pensem nas feridas/Como rosas } \\
& \text { cálidas/Mas oh não se esqueçam/Da rosa da rosa/Da rosa de Hiroxima/A rosa } \\
& \text { hereditária/A rosa radioativa/Estúpida e inválida/A rosa com cirrose/A antirrosa } \\
& \text { atômica/Sem cor sem perfume/Sem rosa sem nada (MORAES, 2006). }
\end{aligned}
$$

As ideias expostas no poema podem ser relacionadas com o aspecto enfatizado por Mecke de que os escritores dão atenção particular à Física quando ela traz consequências para a sociedade:

Os escritores dedicam particular atenção à física quando esta tem consequências sociais, económicas ou políticas. [...] ameaça que a fisica moderna representa para o mundo, sobretudo através do desenvolvimento da bomba atómica [...] Estes exemplos literários que todos conhecem realçam a imagem da responsabilidade do cientista (MECKE, 2004, p. 8).

O poeta, ao utilizar o "pensem" repetidas vezes parece convidar o leitor a refletir criticamente sobre as consequências do lançamento do artefato - que só foi possível de ser criado com o desenvolvimento científico - sobre o uso que a humanidade faz da Ciência e das possibilidades que dela decorrem, e parece pedir ainda que não nos esqueçamos desse fato na história: "Mas oh não se esqueçam”.

Observam-se também metáforas relacionadas à rosa "A rosa hereditária/A rosa radioativa/Estúpida e inválida/A rosa com cirrose/A antirrosa atômica", que deixam a imaginação do leitor flutuar.

Outro poema escolhido é o Poema de ser ou não ser, de António Gedeão ${ }^{5}$ (GEDEÃO, 2007):

São ondas ou corpúsculos?/Sim ou não?/São uma ou outra coisa, ou serão ambas?/São <ou> ou serão <e>?/Ou tudo se passa como se?//Percorrem

\footnotetext{
${ }^{5}$ Rómulo de Carvalho (1906-1997) poeta e professor de Ciências (Física-Química) português.
} 
velozmente órbitas certas/as quais existem só quando as percorrem./Velozmente. Será?/Ou talvez não se movam, o que depende/do estado em que se encontre quem observa.//Assim prosseguem rotineira marcha/na paz podre do tempo./Oh! O tempo!/Até que, de repente,/por exigências igualmente certas,/num sobressalto histérico,/saltam da certa órbitale vão fazer o mesmo noutra certa/tão certa como a outra./e assim prosseguem/na paz podre do tempo.//Eis senão quando,/como pera num charco ou estrela que deflagra,/irrompem no vazio,/e o vazio perturbado afunda-se e alteia-se,/e em esferas sucessivas, pressurosas,/vão alagando o espaço,/primeiro o espaço próximo/depois o mais distante,/e seguem sempre, sempre, avante, sempre avante,/em quantas direcções se lhe apresentam./Sim, ou não?//Estou à janela/e vejo muito ao longe a linha do horizonte.//Ser ou não ser?/Eis a questão (GEDEÃO, 2007).

No poema, António Gedeão refere-se à dualidade onda-partícula, questionando se o que é onda também poderia ser partícula e vice-versa. No caso de Gedeão, Sena (2007, p. 65) ressalta que nos "deparamos com um poeta de cultura científica", e que se a formação científica do poeta "não fosse conhecida, se deduziria das ocorrências vocabulares especializadas". Não podemos esquecer que a Ciência e a Literatura são ambas criativas e complementares para a exploração (NEPOTE, 2012). E que "é possível rastrear em qualquer época da história escritores inclinados à ciência, assim como cientistas atentos à literatura. Afinal, ambos são leitores e escritores" (NEPOTE, 2012, p. 20).

Ao abordar a questão da dualidade, Gedeão utiliza "ou" ou "e" no quarto verso para questionar se a existência de uma característica excluiria ou complementaria outra. Na estrofe seguinte, questiona se há ou não um movimento e se o mesmo é veloz, e nos versos "Ou talvez não se movam, o que depende" "do estado em que se encontre quem observa" faz alusão ao fato de que na Mecânica Quântica fazer essa medida já seria interferir no resultado.

Depois, traz a ideia da quantização da radiação eletromagnética, do fóton. Ou seja, se luz é absorvida ou emitida por um corpo, isso irá ocorrer no nível atômico. Nos versos "saltam da certa órbita" "e vão fazer o mesmo noutra certa" "tão certa como a outra" "e assim prosseguem" o poeta pode estar se referindo ao que ocorre quando energia é cedida por um fóton.

Sena (2007, p. 59) aponta que "a linguagem especializada que aparece nos poemas de António Gedeão deriva da física, da química, das ciências naturais em geral (biologia, mineralogia, petrografia)". O poema em questão possibilita reflexões acerca da Mecânica Quântica, a ideia da dualidade, as questões históricas sobre estudos e debates quanto à natureza da luz, experimentos realizados nesse contexto, cientistas envolvidos com essa temática e suas teorias. Para Silva e Devecchi (2017, p. 3) além da riqueza em termos científicos o poema permite "discussões e relações da Física com outros campos de conhecimento como a Literatura e a Filosofia". 
Por último, trazemos Cecília Meireles. O Espaço (MEIRELES, 2005) foi escrito em 1963 e originalmente publicado no livro O Estudante Empírico em meados da década de 1960:

Daqui por diante, o céu não é mais apenas o reino das nuvens,/morada do sol, da lua e das estrelas,/lugar dos anjos e de Deus.//Entre os desenhos da chuva e do cometa exótico,/há mil traçados invisíveis, em todas as direções./Numa prisão de retas e curvas nossos olhos terrenos,/aves angustiadas,/encontram seus esconderijos e limites.//Todo ocupado, o espaço, com seus secretos esquemas; /infinitas leis em todos os rumos./Do olhar à estrela, nada é simples, nada é fácil.//Daqui por diante não mais seremos tranquilos ou felizes/diante do luminoso céu, mas inquietos e humilhados,/certos da nossa reconhecida cegueira:/assim vamos, conduzidos ou perdidos/entre o que vemos e o que sabemos que não vemos (MEIRELES, 2005).

Cecília relata que o espaço em que vivemos não é feito apenas de coisas concretas. Nos versos há "mil traçados invisíveis/infinitas leis em todos os rumos" podemos fazer relação direta com as Leis da Física e utilizadas em aulas de Física, que não passam de abstrações buscando representar e compreender conceitos e situações.

\section{Implicações para o ensino}

Diante das reflexões apresentadas reiteramos que a união entre Física e Poesia permite abordar aspectos referentes à História, às pessoas, à sociedade, estudos científicos, objetos (concretos ou abstratos) que despertam algum tipo de interesse, além de chamar atenção do leitor para refletir sobre algo, aprender um assunto, explorar sua criatividade e imaginação ao usar metáforas e/ou assuntos cheios de mistérios e imprevisões. No contexto do ensino de ciências, Moreira (2002, p. 17) sugere uma discussão interdisciplinar de poemas "de preferência acompanhados de um apanhado histórico das relações entre Ciência e poesia relativas àquele tema, do contexto científico e literário associado e de análises sobre o conteúdo e forma dos poemas".

Para Paixão (1982, p. 12-13) o poeta "tanto pode escrever um longo poema lamentando a morte de milhares de homens, como pode expressar todo o seu sentimento em apenas dois versos, lacônicos e fulminantes [...]. Em curto espaço, o poeta consegue resumir sua visão e transmiti-la com impacto para o leitor". Essa imprevisibilidade de atitude do poeta e o contato com a poesia contribuem para que o estudante perceba que a ciência pode apresentar uma dimensão poética e a poesia (e poemas) pode apresentar uma dimensão científica, elevando seus níveis de percepção, de conhecimento, de autoconhecimento, de expressividade e de reflexão sobre o seu papel na sociedade e na humanidade. 
Diante dos exemplos apresentados, e utilizando como um parâmetro as peculiaridades apontadas por Mecke (2004), entende-se o quão interessante e frutífero pode ser o diálogo entre Física e Poesia.

Mecke (2004) traz ainda quais seriam as consequências didáticas das peculiaridades apontadas anteriormente - e porque não dizer as consequências didáticas que surgem ao unir a Poesia à Física - elaborando as seguintes teses:

I. Metáforas fisicas: Muitos livros de fisicica pecam no que toca ao significado da linguagem e ao uso correcto de imagens e metáforas. Sucede também frequentemente que os fisicos se servem de termos mal escolhidos, os quais despertam nos seus ouvintes associações enganadoras. [...] É indispensável ensinar não só técnicas de cálculo correctas, mas também associações de ideias correctas.

II. Os físicos como personagens literárias: as narrativas e a literatura tornam a fisica interessante e emocionante. Contribuem, portanto, para motivar e para tornar a disciplina mais atraente [...] Numa aula é possivel reflectir, através de exemplos tirados da literatura, sobre a visão que a sociedade tem do físico e da investigação e que valor lhes atribui. Esta sensibilização é indispensável ao nosso próprio conhecimento como fisicos e ao nosso confronto crítico com a disciplina a que nos dedicamos.

III. Física e sociedade: a responsabilidade do físico não se esgota na averiguação da legitimidade em colaborar ou não com a indústria de armamento. A fisica pode também contribuir para desenvolver uma ética da verdade e dos valores humanos [...].

IV. A literatura na mudança da física: a física é parte integrante da nossa cultura. Por que não usar a história da literatura para explicar a história da física? Penso que, nesta linha, se poderiam desenvolver módulos didácticos muito ricos para as aulas de fisica.

V. Todas as ciências têm de ser poetizadas: A literatura e a fisica habitam o mesmo ambiente cultural. Não só a fisica influencia a literatura como vice-versa. Não no sentido de uma causalidade directa, mas sim no de um quadro interpretativo comum, de uma língua comum, com imagens e metáforas comuns. Porque a física vive de metáforas poderosas [...] (MECKE, 2004, p. 13).

Isto posto, os parâmetros supracitados servem também para nortear experiências didáticas unindo Física e Poesia e possibilitar o contato de estudantes e professores com outro lado que a poesia apresenta. Podem instigar estratégias de professores de Física que almejam inserir esse diálogo em sala de aula - onde há lugar para o lado "humano" da Física, para a criatividade, para o sensível e o belo - pois "a sensibilidade estética pode ser início, motivação e fundamento da sensibilidade científica, que motiva e inspira a busca do saber" (RANGEL; ROJAS, 2014, p. 73).

De modo geral, a partir da inserção e análise de um poema no ensino de Física é possível dar ênfase não só a aspectos científicos, mas epistemológicos, sociais, históricos e artísticos. Professoras e professores podem enfatizar com seus alunos o que estiver presente 
tanto nos versos quanto nas entrelinhas, estimulando debates e reflexões. Desse modo, não tem importância apenas a aprendizagem de conteúdos científicos, mas também a leitura, interpretação de texto e criatividade. Os professores podem explorar possibilidades didáticas de maneira crítica, e é oportuno lembrar que:

A literatura não é escrita para descrever a física, mas sim para a utilizar metaforicamente e, se possível, para alargar o seu âmbito. Por isso não devemos ficar muito perturbados quando as relações físicas são utilizadas de forma incorrecta. O uso literário da física torna-se interessante pelo alargamento do sentido dos termos físicos (MECKE, 2004, p. 7).

Para além, o poema e a poesia intrínseca podem ser uma experiência de conhecimento.

\section{Referências}

ARAUJO-JORGE, T. C.; MEIRELleS, R. M. S.; LUZ, M. R. M. P.; VIEIRA, G. J.; KAMEL, C. L.; GROSSMAN, E.; CAMPOS, M. V.; OLIVEIRA, D. F.; LA ROCQUE, L. Ciência e arte como linha de pesquisa no Instituto Oswaldo Cruz/Fiocruz. In: MASSARANI, L. (Org.) Memórias do Simpósio Ciência e Arte 2006. Rio de Janeiro: Museu da vida/ Casa de Oswaldo Cruz/Fiocruz, p. 71-76, 2007.

BANDEIRA, M. Meus Poemas Preferidos. São Paulo: Editora Ediouro, 2005. 208 p.

BOSI, A. O ser e o tempo da poesia. 6. ed. São Paulo: Companhia das Letras, 2000. 280 p.

COLLINS, P. Rhyme and reason: The Victorian poet scientists. New Scientist, edição 2844, 24 dez 2011. Seção Feature. Disponível em: <https://www.newscientist.com/article/1966743rhyme-and-reason-the-victorian-poet-scientists/\#.U45GAvl_uSo>. Acesso em: 01 set. 2019.

FIORIN, J. L. Em busca de sentido: estudos discursivos. São Paulo: Contexto, 2015. 186 p. GARCIA-POSADA, M. Explorando el mundo - Poesía de la ciencia. Espanha: Gadir Editorial, 2006. 303, p.

GEDEÃO, A. Obra Completa. 2. ed. Lisboa: Relógio D’Água Editores, 2007. 730 p.

GOLDSTEIN, N. S. Versos, sons, ritmos. São Paulo: Editora Ática, 2006. 111 p.

LYRA, P. Conceito de Poesia. São Paulo: Editora Ática, 1986. Sério Princípios 57. 96 p. 
MARX, K. O Capital: crítica da economia política: livro I. Tradução: Reginaldo Sant'Anna. 33. ed. Rio de Janeiro: Civilização Brasileira, 2014. 570 p.

MECKE, K. R. A Imagem da Literatura na Física. Gazeta da Física, v. 27, n. 4, p. 4-13, nov. 2004.

MEIRELES, C. O Estudante Empírico. Rio de Janeiro: Nova Fronteira, 2005. 128 p.

MOISÉS, M. A criação literária: Introdução à Problemática do Literatura. São Paulo: Editora Edições Melhoramentos, 1968. 334 p.

MOISÉS, M. A criação poética. São Paulo: Melhoramentos, 1977. 156 p.

MORAES, V. Antologia Poética. São Paulo: Companhia das Letras, 1992. 328 p.

MORAES, V. Nova Antologia Poética. São Paulo: Companhia das Letras, 2006. 251 p.

MOREIRA, I. C. Poesia na Sala de Aula de Ciências? Física na Escola, v. 3, n. 1, p. 17-23, 2002.

MORICONI, I. Como e por que ler a poesia brasileira do século XX. Rio de Janeiro: Objetiva, 2002. $156 \mathrm{p}$.

NEPOTE, J. Almanaque: histórias de ciência e poesia. Campinas: Editora da Unicamp, 2012. 392 p.

PAIXÃO, F. O que é Poesia? São Paulo: Editora Brasiliense, 1982. 104 p.

PAZ, O. O Arco e a Lira: o poema, a revelação poética, poesia e história. São Paulo: Cosac Naify, 2012. 352 p.

PERISSÉ, G. Literatura e Educação. Belo Horizonte: Autêntica, 2006. 146 p.

RANGEL, M.; ROJAS, A. A. Ensaio sobre arte e ciência na formação de professores. Revista Entreideias, Salvador, v. 3, p. 73-86, jul./dez. 2014.

REIS, J. C.; GUERRA, A.; BRAGA, M.: Ciência e arte: relações improváveis? História, Ciências, Saúde - Manguinhos, v. 13, (suplemento), p. 71-87, 2006.

SÁ-CARNEIRO, M. Obra completa. Rio de Janeiro: Editora Nova Aguilar, 1995. 
SENA, J. A Poesia de António Gedeão. In: GEDEÃO, A. Obra Completa. Lisboa: Editora Relógio D’Água, 2007. p. 43-88.

SILVA, C.; DEVECCHI, P. Análise sobre o "Poema de ser ou não ser" e suas potencialidades didáticas para o ensino de ciências/física. Ciência em tela, v. 10, n. 2, p. 1-9, 2017.

SNOW, C. P. As Duas Culturas e uma segunda leitura. Tradução: SOUZA, G. G.; NETO, R. A. R. São Paulo: Editora da Universidade de São Paulo, 2015. 136 p.

VASCONCELOS, R. Painting the Nails with a Parisian Polish: Modern Dissemination and Central Redemption in the Poetry of Mário de Sá-Carneiro. Pessoa Plural - a Journal of Fernando Pessoa Studies, n. 4, p. 129-151, 2013.

WHEELRIGHT, P. Metaphor and Reality. Bloomington, Indiana University Press, 1968.

WILSON, S. Ciência e Arte - Olhando para trás/olhando para a frente. In: DOMINGUES, D. (Org.), SARETTA et al. (tradução). Arte, Ciência e Tecnologia: passado, presente e desafios. São Paulo: Editora UNESP, 2009. p. 289-498.

ZANETIC, J. Física e Arte: uma ponte entre duas culturas. Pro-posições, v. 17, n. 1, p. 39-57, jan./abr. 2006.

ZANETIC, J. Física e Cultura. Ciência e Cultura, v. 57, n. 3, p. 21-24, 2005. 